\title{
Effects of olive oil polyphenols on fatty acid synthase gene expression and activity in human colorectal cancer cells
}

\author{
Maria Notarnicola $\cdot$ Simona Pisanti $\cdot$ Valeria Tutino $\cdot$ Domenica Bocale $\cdot$ \\ Maria Teresa Rotelli $\cdot$ Antonio Gentile $\cdot$ Vincenzo Memeo $\cdot$ Maurizio Bifulco • \\ Enzo Perri · Maria Gabriella Caruso
}

Received: 9 March 2010/Accepted: 4 May 2010/Published online: 16 May 2010

(C) Springer-Verlag 2010

\begin{abstract}
Oleuropein (OL) and hydroxytyrosol (HT), the main olive oil polyphenols, possess anti-proliferative effects in vitro. Fatty acid synthase, a key anabolic enzyme of biosynthesis of fatty acids, plays an important role in colon carcinoma development. Our aim was to investigate whether gene expression of FAS, as well as its enzymatic activity, is regulated by HT and OL in two human colon cancer cell lines, as HT-29 and SW620. In addition, we investigated the effects of these polyphenols on growth and apoptosis in these cells. FAS gene expression and activity in treated HT-29 and SW620 cells were evaluated by realtime PCR and radiochemical assay, respectively. Cell growth and apoptosis, after polyphenols treatment, were measured by MTT test and flow cytometry, respectively. The inhibition of proliferation, detected after HT treatment, was mediated by an inhibition of FAS expression and its enzymatic activity in SW620 cells, while the anti-proliferative effect in HT-29 cells seems to be independent from FAS. OL exerted an anti-proliferative effect only on SW620 cells with a mechanism which excluded FAS.
\end{abstract}

M. Notarnicola $\cdot$ V. Tutino · A. Gentile · M. G. Caruso ( $\square)$ Laboratory of Biochemistry, National Institute for Digestive Diseases "S. de Bellis", Via della Resistenza, 70013 Castellana Grotte, Bari, Italy

e-mail: gabriella.caruso@irccsdebellis.it

\section{S. Pisanti - M. Bifulco}

Department of Pharmaceutical Sciences,

University of Salerno, Salerno, Italy

D. Bocale $\cdot$ M. T. Rotelli $\cdot$ V. Memeo

D.E.T.O. Division of Surgery, University of Bari, Bari, Italy

E. Perri

CRA-Research Center for Olive Growing and Olive Oil Industry, Rende (CS), Italy
Olive oil polyphenols used were able to induce apoptosis in both cell lines studied. The increase of apoptosis in these cells was accompanied by the block of cell cycle in the $\mathrm{S}$ phase. This study demonstrates that HT and OL may induce anti-proliferative and pro-apoptotic effects only in certain human colorectal cancer cell types. These effects are FAS mediated only in SW620 cells after treatment with HT.

Keywords Hydroxytyrosol - Oleuropein ·

Fatty acid synthase $\cdot$ Colorectal cancer

\section{Introduction}

Olive oil is a key component of the Mediterranean diet and is believed to beneficially affect numerous biological processes [22, 29]. Epidemiological studies have shown a lower incidence of atherosclerosis, cardiovascular diseases and certain kinds of cancer, in particular colon cancer, in the Mediterranean countries compared to those in Northern Europe [7, 21, 25].

In this respect, olive oil consumption has been demonstrated to reduce the incidence of aberrant crypt foci in azoxymethane-treated rats [28]. Furthermore, olive oil is able to down-regulate the expression of COX-2 and BCL-2 proteins that play a crucial role in colorectal carcinogenesis [2].

In particular, olive oil healthy effects can be attributed not only to the higher relationship between unsaturated and saturated fatty acids, but also to the antioxidant property of its phenolic compounds [18]. Among phenolic compounds, oleuropein (OL) and hydroxytyrosol (HT) are those which give to the extra-virgin olive oil its bitter, pungent taste and possess powerful antioxidant properties in vitro [5]. As 
antioxidants, polyphenols may protect cell constituents against oxidative damage and act as highly effective chemopreventive agents $[4,16,17]$.

OL, the most abundant of the phenolic compounds in olives, inhibits cell growth, motility and invasiveness [6]. OL also exerts direct anti-tumor effects and has been considered as a new class of anti-cancer compounds which target multiple steps in cancer progression [6]. Hydrolysis of OL, which occurs during olive oil storage, results in the formation of HT, tyrosol and ethanol. HT and OL scavenge free radicals and inhibit low-density lipoprotein (LDL) oxidation $[17,18,27]$. These two phenols display dosedependent activity and are considered potent antioxidants also demonstrating activity in the micro-molar range [28].

A substantial subset of common human cancers, including colon cancer, express elevated levels of fatty acid synthase (FAS), a key anabolic enzyme that catalyzes the terminal steps in the novo biosynthesis of fatty acids $[8,13$, 20, 23, 24]. In breast and prostate carcinomas, high levels of FAS expression are associated with poor clinical outcome, suggesting a relationship between FAS expression and tumor aggressiveness [1, 24]. FAS expression also appears to play an important role in the growth and pathogenesis of colon carcinoma [20]. Previously, we demonstrated that FAS activity levels, as well as the expression of its mRNA are up-regulated in colorectal cancer tissues [14]. The difference in expression between normal tissues and cancer has led to the development of a novel strategy for antineoplastic intervention. In fact, recent studies show that pharmacological inhibition of FAS led to selective cytotoxicity in FAS-over-expressing cancer cell lines [9]. Increased levels of FAS expression observed in carcinoma cells compared with most normal cells led to the notion that this pathway may represent a potential target for drug development.

In this study, our aim was to investigate whether gene expression of FAS, as well as its enzymatic activity, is regulated by HT and OL in two human colon cancer cell lines, as HT-29 and one lymph node metastatic cell line, SW620. In addition, we investigated the effects of HT and OL on growth and apoptosis in these cell lines.

\section{Materials and methods}

\section{Cell culture conditions}

The human colon adenocarcinoma cell lines HT-29 and SW620 were obtained from ICLC (IST, Genoa, Italy). SW620 cells were grown in Dulbecco's modified Eagle's medium, while HT29 in Mc COY'S 5A, supplemented with glucose $(4.5 \mathrm{~g} / \mathrm{L})$, sodium pyruvate $(1.1 \mathrm{~g} / \mathrm{L})$, penicillin/streptomycin/L-glutamine $(1 \times)$ and inactivated fetal bovine serum (FBS 10\%) in a humidified atmosphere of $95 \%$ air, $5 \% \mathrm{CO}_{2}$ at $37^{\circ} \mathrm{C}$.

FAS gene expression analysis

Analysis of gene expression was performed in HT-29 and in SW620 treated with HT and OL glycoside obtained from Extrasynthe'se Co. Z. I. Lyon Nord, Genay, France and gifted generously from Prof. Perri [CRA-Research Center for olive growing and olive oil industry, Rende (CS), Italy] at different concentrations $(10,25,50$ and $100 \mu \mathrm{M})$ after 24 and $72 \mathrm{~h}$ of exposure. Each cell line was washed twice in phosphate-buffered saline (PBS) and then trypsinized and centrifuged at low speed. The cell pellets were resuspended in 0.3-ml pure distilled water and used for RNA extraction.

Total cell RNA was extracted using Tri-Reagent (Mol. Res. Center Inc., Cincinnati, Ohio, USA), following the manufactures' instruction. About $2 \mu \mathrm{g}$ total cell RNA, extracted from both the control and treated cells, was used for cDNA synthesis. Reverse transcription (RT) was carried out in $20 \mu \mathrm{l}$ of the final volume at $41^{\circ} \mathrm{C}$ for $60 \mathrm{~min}$, using $30 \mathrm{pmol}$ antisense primer (FAS sense $5^{\prime}$-TAT GCT TCT TCG TGC AGC AGT T- $3^{\prime}, F A S$ antisense 5'-GCT GCC ACA CGC TCC TCT AG- ${ }^{\prime}, \beta$-actin sense $5^{\prime}$-AAA GAC CTG TAC GCC AAC ACA GTG CTG TCT GG-3', $\beta$-actin antisense $5^{\prime}$-CGT CAT ACT CCT GCT TGC T GAT CCA CAT CTG C- $3^{\prime}$ ) for analyses of the FAS and the $\beta$-actin gene. The $\beta$-actin gene was utilized as an internal control and was chosen as a reference gene because it is a housekeeping gene.

Real-time PCRs were performed in $25-\mu l$ final volume containing $2-\mu l$ cDNA, master mix with SYBR Green (iQ SYBR Green Supermix; Bio-Rad, Milan, Italy) and sense and antisense primers for FAS gene and $\beta$-actin gene (Table 1).

Table 1 Assessment of cell cycle analysis and apoptosis in SW620 cell line treated with HT (a) and OL (b) for $72 \mathrm{~h}$

\begin{tabular}{lcclll}
\hline SW620 & $\begin{array}{l}\text { Control } \\
(\%)\end{array}$ & $\begin{array}{l}10 \mu \mathrm{M} \\
(\%)\end{array}$ & $\begin{array}{l}25 \mu \mathrm{M} \\
(\%)\end{array}$ & $\begin{array}{l}50 \mu \mathrm{M} \\
(\%)\end{array}$ & $\begin{array}{l}100 \mu \mathrm{M} \\
(\%)\end{array}$ \\
\hline \multicolumn{4}{l}{ Hydroxytyrosol (a) } \\
G1 & 49 & 21 & 17 & 4.5 & nd \\
S & 50 & $78^{*}$ & $82^{*}$ & $95^{*}$ & nd \\
G2/M & 1 & 1 & 1 & 0.5 & nd \\
Apoptosis & 12 & 20 & 20 & 18.6 & $53^{*}$ \\
Oleuropein (b) & & & & \\
G1 & 49 & 37 & 34.5 & 30 & nd \\
S & 50 & 62 & 65 & 69 & nd \\
G2/M & 1 & 1 & 0.5 & 1 & nd \\
Apoptosis & 12 & 23 & 21 & 21 & $60^{*}$ \\
\hline
\end{tabular}

$P$ value was determined by one way analysis with Dunnett's post test $* P<0.05$ versus control 
Real-Time PCR was carried out with iCycler Thermal Cycler System apparatus (Bio-Rad) using the following parameters: 1 cycle of $95^{\circ} \mathrm{C}$ for $1 \mathrm{~min}$ and $30 \mathrm{~s}$, followed by 45 cycles at $94^{\circ} \mathrm{C}$ for $10 \mathrm{~s}, 55^{\circ} \mathrm{C}$ for $10 \mathrm{~s}$ and $72^{\circ} \mathrm{C}$ for $30 \mathrm{~s}$ and a further melting curve step at $55-95^{\circ} \mathrm{C}$ with a heating rate of $0.5^{\circ} \mathrm{C}$ per cycle for 80 cycles. The PCR products were quantified by external calibration curves, one for each tested gene, obtained with serial dilution of known copy number of molecules $\left(10^{2}-10^{7}\right.$ molecules $)$. All expression data were normalized by dividing the amount of target by the amount of $\beta$-actin used as internal control for each sample. The specificity of the PCR product of each tested gene was confirmed by gel electrophoresis.

\section{FAS activity assay}

FAS enzymatic activity was evaluated in HT-29 and in SW620 treated with HT and OL at different concentrations $(10,25,50$ and $100 \mu \mathrm{M})$ for 24 and $72 \mathrm{~h}$. Parallel experiments were conducted in untreated control cells.

The cells were washed twice in PBS and then trypsinized and centrifuged at low speed. The cell pellets were resuspended in $20 \mathrm{mM}$ Tris- $\mathrm{HCl} \mathrm{pH} 7.5,1 \mathrm{mM}$ DTT, $1 \mathrm{mM} \mathrm{MgCl}{ }_{2}$ and $1 \mathrm{mM}$ EDTA and centrifuged at $10,000 \mathrm{~g}$ for $10 \mathrm{~min}$ at $4^{\circ} \mathrm{C}$. Sample protein content was determined using Lowry's method. An aliquot of supernatant (50 $\mu \mathrm{l})$ was preincubated with $100 \mathrm{mM}$ potassium phosphate buffer $\left(\mathrm{pH} 7\right.$ ) for $15 \mathrm{~min}$ at $37^{\circ} \mathrm{C}$. Subsequently, $20 \mu \mathrm{l}$ of reaction mix [2.5 mM NADPH, $1.25 \mathrm{mM}$ acetyl-CoA, $1.25 \mathrm{mM}$ malonyl-CoA and $0.02 \mathrm{mM} 2-{ }^{14} \mathrm{C}$-malonyl-CoA $(52 \mathrm{mCi} / \mathrm{mmol}$, Amersham Biosciences, Little Chalfont UK)] was added, and samples were incubated for $10 \mathrm{~min}$ at $37^{\circ} \mathrm{C}$. Reactions were stopped by the addition of $500 \mu \mathrm{l}$ $1 \mathrm{~N} \mathrm{HCl} /$ methanol (6:4 v:v); fatty acids were extracted with $1 \mathrm{ml}$ of petroleum ether and incorporation of $2-{ }^{14} \mathrm{C}$-malonyl-CoA was analyzed by scintillation counting. FAS activity was expressed as picomoles of incorporated $2-{ }^{14} \mathrm{C}$-malonyl-CoA per minute per milligram of total proteins ( $\mathrm{pmol} / \mathrm{min} / \mathrm{mg}$ protein). Parallel samples were assayed to evaluate total and non-specific radioactivity. In all experiments, enzyme assays were carried out in duplicate. The coefficient percentages of intra- and interassay variation were 3 and $4 \%$, respectively.

\section{Cell viability assay}

The viability of HT-29 and SW620 cells treated with HT and OL was determined by the standard 3-(4,5-Dimethylthiazol2-yl)-2,5-diphenyltetrazolium bromide (MTT) assay. Cells were plated $\left(15 \times 10^{4}\right.$ per well) in 96-well plates and incubated overnight at $37^{\circ} \mathrm{C}$. The phenolic compounds were dissolved in methanol $2 \%$ (10 mM, stock solution) and added to the cell culture medium at a concentration not exceeding $0.1 \%(\mathrm{v} / \mathrm{v})$; their effects on cell proliferation were studied at various concentrations $(10,25,50$ and $100 \mu \mathrm{M})$ and at different time points (24 and $72 \mathrm{~h})$. The MTT assay was done in quadruplicate for each drug concentration used. At appropriate intervals, $10 \mu \mathrm{l} \mathrm{MTT}$ solution was added to each well and incubated for $4 \mathrm{~h}$ at $37^{\circ} \mathrm{C}, 5 \% \mathrm{CO}_{2}$. The supernatant was removed, and $100 \mu \mathrm{l}$ of a mixture of DMSO/ethanol (1/1) was then added. Plates were then read at 570-nm wavelength using a microplate reader (Multiskan Ascent, ThermoLab Systems). Percentage of growth inhibition was determined by comparing the cell density in the drug-treated cells with that in the untreated cell controls in the same incubation period [percentage of inhibition = cell density of a treated group/ cell density of the control group]. All experiments were repeated three times.

\section{Cell stimulation}

To study the effects of HT and OL on cell cycle, every cell line (HT29 and SW620) was seeded $\left(1.5 \times 10^{6}\right)$ in cell culture dishes $(100 \times 20 \mathrm{~mm})$ in complete growth medium (DMEM or Mc COY'S containing $10 \%$ fetal bovine serum, antibiotics and L-glutamine). The experiments were performed with sub-confluent (70-80\%) cultures to avoid the effects of cell density on cell cycle and gene expression. After $24 \mathrm{~h}$, the cells were washed once with PBS and preconditioned for $24 \mathrm{~h}$ at $37^{\circ} \mathrm{C}$ in $8 \mathrm{ml}$ of DMEM containing $1 \%$ FBS. After preconditioning, phenolic compounds were then added at various concentrations $(10,25$, 50 and $100 \mu \mathrm{M}$ ) for $72 \mathrm{~h}$.

For cell cycle determination, at the end of incubation, cells were harvested using trypsin/EDTA 1X (Invitrogen), collected with supernatant and counted with trypan blue. Cells were then washed twice with PBS. Pellet was resuspended in $300 \mu \mathrm{l}$ of PBS and fixed using $700 \mu \mathrm{l}$ of absolute ethanol.

Assessment of apoptosis and cell cycle analysis

To investigate the nature of growth inhibition induced by HT and OL, cell cycle phase distribution and apoptosis quantification were assessed by flow cytometry in HT-29 and SW620 treated with increasing doses of polyphenols (10, 25, 50 and $100 \mu \mathrm{M})$ for $72 \mathrm{~h}$. Cells were collected, fixed in $300 \mu \mathrm{l}$ of PBS plus $700 \mu \mathrm{l}$ of ethanol and kept at $-20^{\circ} \mathrm{C}$ overnight. Propidium iodide $(10 \mu \mathrm{g} / \mathrm{ml})$ in PBS containing $100 \mathrm{U} / \mathrm{ml}$ DNase-free RNase A was added to the cells; after $15 \mathrm{~min}$ at room temperature, cells were subjected to flowcytometric analysis. Data acquisition was performed in a FACS Calibur flow-cytometer using CellQuest software (BD, Biosciences, Franklin Lakes, NJ). Analysis was performed using ModFit LT version 3.0 from 
Verity Software House, Inc. (Topsham, ME). Each sample was analyzed using 10,000 events corrected for debris and aggregate populations.

\section{Statistical analysis}

The significance of the differences in FAS gene expression and activity, as well as in cell cycle analysis and percentage of apoptosis between the control group and each experimental group, was evaluated using one-way analysis of variance and the Dunnett's post test. Differences were considered significant at a 5\% probability level.

\section{Results}

Exposure of SW-620 cells after $24 \mathrm{~h}$ to increasing concentrations of HT and OL (from 10 to $100 \mu \mathrm{M}$ ) caused no effect on FAS gene expression and activity (data not shown). The treatment with HT, but not with OL, elicited a significant reduction both in gene expression and in activity of FAS in these cells after $72 \mathrm{~h}$ of exposure, starting from $10 \mu \mathrm{M}$ of concentration (Fig. 1a and b) $(P<0.05$, Dunnett's test).
In SW620, the treatment with different concentrations of $\mathrm{HT}$ and OL for $24 \mathrm{~h}$ did not produce an anti-proliferative action (data not shown). On the contrary, an evident antiproliferative effect in SW-620 cell line was present after $72 \mathrm{~h}$ of exposure to HT and OL that became significant at concentrations starting from $10 \mu \mathrm{M}$ for both compounds (Fig. 2), $(P<0.05$, Dunnett's test). Moreover, HT and OL also gave rise to a marked pro-apoptotic effect (\% of subG1 positive cells) in SW-620 cells after $72 \mathrm{~h}$ of treatment, and a cell cycle arrest in the $S$ phase of the cell cycle compared to the untreated control cells was observed at concentration starting from $10 \mu \mathrm{M}$ of HT (Table 1a and b), $(P<0.05$, Dunnett's test $)$.

Exposure of HT-29 cells after 24 and $72 \mathrm{~h}$ to increasing concentrations of HT and OL (from 10 to $100 \mu \mathrm{M}$ ) caused no effect on FAS gene expression and activity (data not shown).

After $24 \mathrm{~h}$, HT and OL did not cause an anti-proliferative action in HT-29 cells (data not shown). On the contrary, the cell growth inhibition, in these cells, was present after $72 \mathrm{~h}$ of exposure to HT, but not OL, and the inhibitory effect was only significant at higher concentrations of HT (Fig. 3) $(P<0.05$, Dunnett's test). Moreover, HT and OL also gave rise to a slight pro-apoptotic effect (\% of sub-G1
Fig. $1 \mathrm{HT}$ and OL effects on FAS gene expression (panel a) and activity (panel $b$ ) in SW620 cells after $72 \mathrm{~h}$ of treatment. $P$ value was determined by oneway analysis with Dunnett's post test. $* P<0.05$ versus control
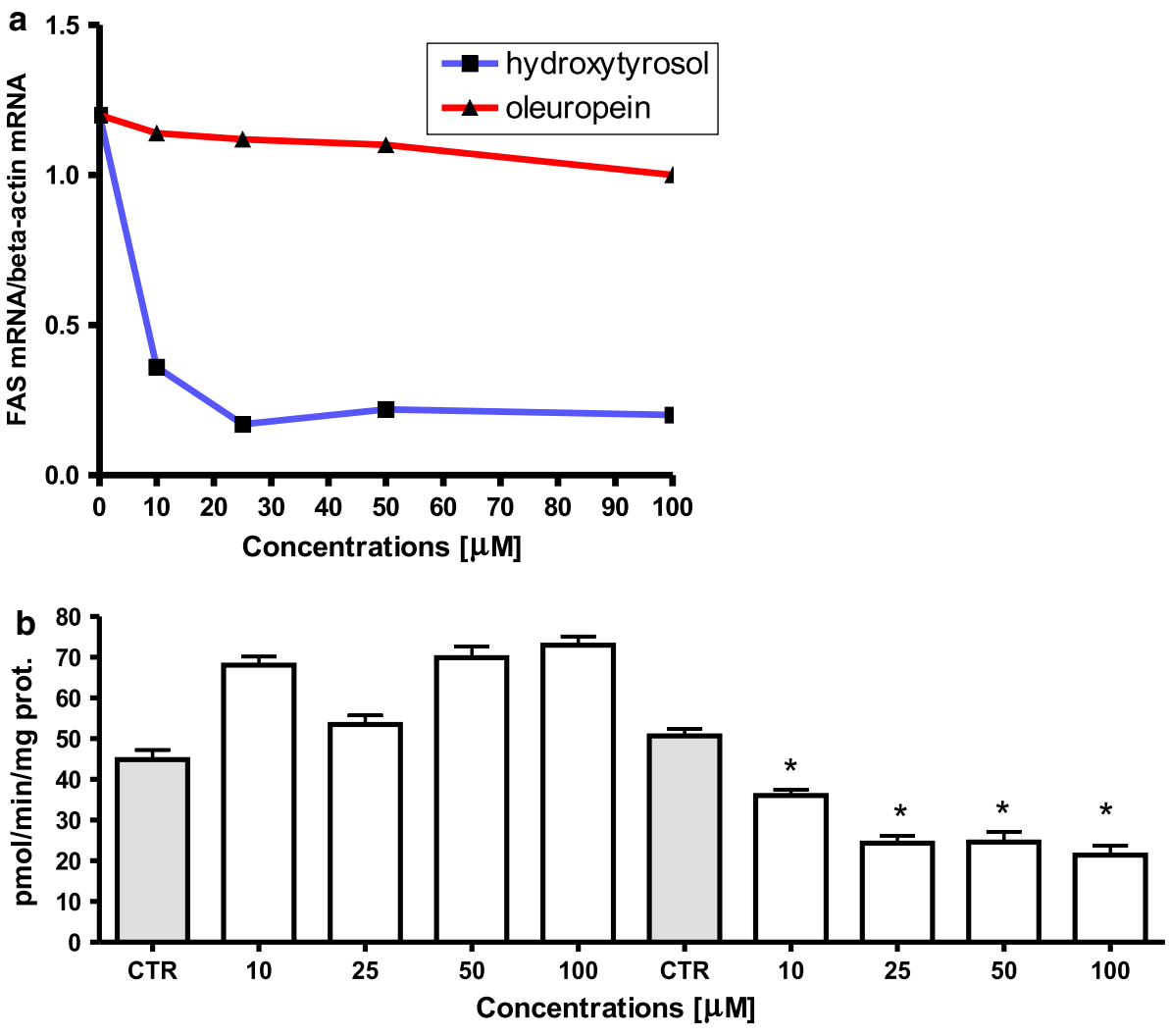


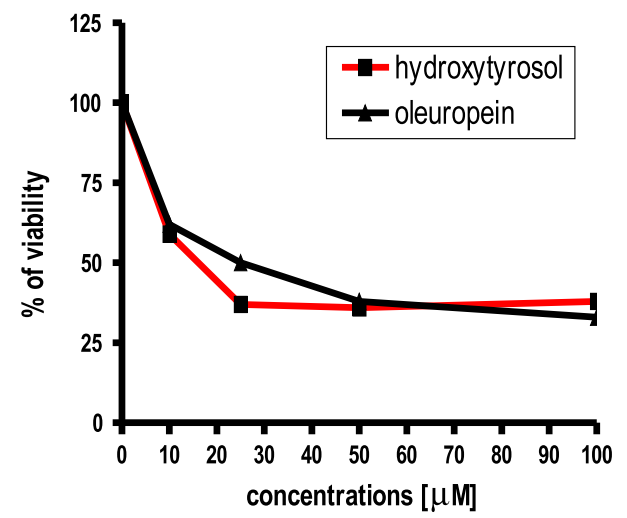

Fig. 2 Effect of increasing HT and OL concentrations on the conversion of MTT-tetrazolium salt in SW620 cells. A significant anti-proliferative action was observed starting from $10 \mu \mathrm{M}(P<0.05$, Dunnett's post test)

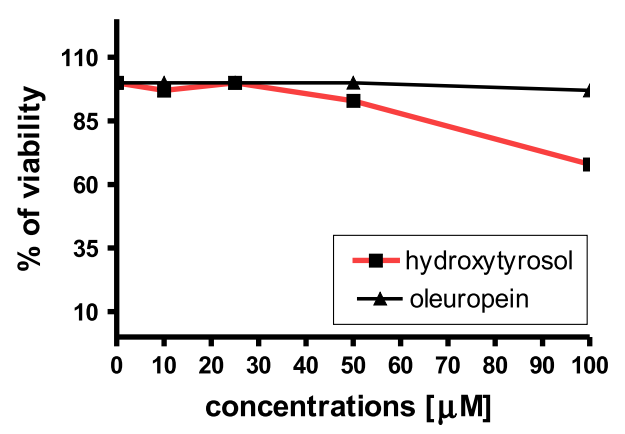

Fig. 3 Effect of increasing HT and OL concentrations on the conversion of MTT-tetrazolium salt in HT-29 cells. A significant anti-proliferative action was observed at $100 \mu \mathrm{M}$ of HT $(P<0.05$, Dunnett's post test)

positive cells) in HT-29 cells after $72 \mathrm{~h}$ of treatment, and a slight accumulation in the S phase of the cell cycle compared to the untreated control cells was observed only at higher concentrations (Table $2 \mathrm{a}$ and $\mathrm{b}),(P<0,05$, Dunnett's test).

\section{Discussion}

Our current findings reveal for the first time, to our knowledge, that HT suppresses the expression of FAS, as well as its activity in SW620 human colon cancer cell line. Moreover, this polyphenolic compound significantly inhibits cell proliferation in SW620 through a pro-apoptotic effect. The exposure to increasing concentrations of HT led to a remarkable reduction in cell proliferation in HT-29 cells, too. In these cells, the reduction in cancer cell growth detected after HT exposure seems to be independent from FAS gene expression and its enzymatic activity.
Table 2 Assessment of cell cycle analysis and apoptosis in HT-29 cell line treated with HT (a) and OL (b) for $72 \mathrm{~h}$

\begin{tabular}{llllll}
\hline HT-29 & $\begin{array}{l}\text { Control } \\
(\%)\end{array}$ & $\begin{array}{l}10 \mu \mathrm{M} \\
(\%)\end{array}$ & $\begin{array}{l}25 \mu \mathrm{M} \\
(\%)\end{array}$ & $\begin{array}{l}50 \mu \mathrm{M} \\
(\%)\end{array}$ & $\begin{array}{l}100 \mu \mathrm{M} \\
(\%)\end{array}$ \\
\hline \multicolumn{2}{l}{ Hydroxytyrosol (a) } \\
G1 & 62 & 63 & 60 & 57 & 47 \\
$\mathrm{~S}$ & 37 & 36 & 39.4 & 42 & 52 \\
G2/M & 1 & 1 & 0.6 & 1 & 1 \\
Apoptosis & 17.9 & 25.8 & 20.2 & 35.2 & $43^{*}$ \\
Oleuropein (b) & & & & \\
G1 & 60 & 49.5 & 60 & 58 & 59 \\
S & 37 & 50 & 39 & 41 & 40 \\
G2/M & 1 & 0.5 & 1 & 1 & 1 \\
Apoptosis & 14.5 & 20.5 & 30 & 29.8 & $37.3 *$ \\
\hline
\end{tabular}

$P$ value was determined by one-way analysis with Dunnett's post test * $P<0.05$ versus control

In addition, our findings clearly show that OL exerts an anti-proliferative effect only on SW620 cells eliciting a slight pro-apoptotic effect ( $\%$ of sub-G1 positive cells) in both cell lines.

Nevertheless, caution must be applied when extrapolating in vitro results into clinical practice, the findings of this study have biological relevance since the changes on cultured cancer cells were observed at polyphenol concentrations corresponding to those daily consumed in some Mediterranean areas.

The two studied cell lines show a different response to polyphenols treatment, probably due the fact that HT and OL can exert differential effects, depending on the genetic or morphological make-up of the cells upon which they act. Low grade of differentiation and K-ras mutation [3] could make SW620 cells more sensitive to the induction of apoptosis, whereas HT-29 cells, negative for K-ras mutation, seem to be more resistant. Experimental data $[5,6,19]$ suggest a multifaceted action of polyphenols on the modulation of cell signals and biochemical pathways involved in cell survival and cell death. These effects depend on the concentration of polyphenols, the cell system, the cell age and the type or stage of degenerative process.

The down-regulation of FAS observed after HT treatment in SW620 suggests that FAS might be a molecular target for anti-proliferative activity of olive oil polyphenols in a metabolically defined subset of colon cancer.

FAS has been implicated in the natural history of breast cancer largely through its connection with the activity and/or expression of key cancer-related oncogenes such as the Type 1 receptor tyrosine kinase HER2 [10, 11]. Transcriptomic, proteomic and functional analyses have demonstrated that HER2 overexpression leads to constitutive up-regulation and maintenance of an exacerbated endogenous FA biogenesis, a 
"lipogenic benefit" in terms of enhanced breast cancer cell proliferation, survival, chemoresistance and metastasis [12].

FAS expression appears also to play an important role in the growth and pathogenesis of colon carcinoma [20, 26]. Elevated expression of FAS protein and higher FAS activity have been shown in colorectal cancer [14, 20, 26], demonstrating that the entire fatty acid synthesis pathway is up-regulated in colorectal carcinoma. Moreover, tumoral FAS overexpression has been associated with patient outcome in colon cancer [15].

It has been proposed that inhibition of FAS by pharmacologic agents is an effective way of reducing proliferation rate and inducing apoptosis in colon cancer cells [30]. Moreover, studies in prostate and ovarian cancer cells have demonstrated that FAS inhibitors may provide a feasible tumor-targeting strategy across a wider spectrum of tumors [30].

Naturally occurring olive oil polyphenols through their ability to suppress the lipogenic enzyme FAS may provide well-tolerated novel cancer therapies, particularly in metabolic disorders-related tumors, as colon cancer.

In conclusion, our findings demonstrate that the main olive oil polyphenols may induce anti-proliferative effects in human colorectal cancer cells. These inhibitory effects on cell growth are mediated by FAS in certain human colorectal cancer cell types, suggesting that more differentiated and specialized cells could be more able to control the expression of genes involved in cell proliferation.

\section{References}

1. Alo PL, Visca P, Marci A, Mangoni A, Botti C, Di Tondo U (1996) Expression of fatty acid synthase (FAS) as a predictor of recurrence in stage I breast carcinoma patients. Cancer 77:474-482

2. Corona G, Deiana M, Incani A, Vauzour D, Dessì MA, Spencer JPE (2007) Inhibition of p38/CREB phosphorylation and COX-2 expression by olive oil polyphenols underlies thaeir anti-proliferative effects. Biochem Biophys Res Comm 362:606-611

3. Dahan L, Sadok A, Formento JL, Seitz JF, Kovacic H (2009) Modulation of cellular redox state underlies antagonism between oxaliplatin and cetuximab in human colorectal cancer cell lines. Br J Pharmacol 158(2):610-620

4. Fini L, Hotchkiss E, Fogliano V, Graziani G, Romano M, De Vol E et al (2008) Chemopreventive properties of pinoresinol-rich olive oil involve a selective activation of the ATM-p53 cascade in colon cancer cell lines. Carcinogenesis 29:139-146

5. Gill CIR, Boyd A, McDermott E, McCann M, Servili M, Selvaggini R, Taticchi A, Esposto S, Montedoro G, McGlynn H, Rowland I (2005) Potential anti-cancer effects of virgin olive phenols on colorectal carcinogenesis models in vitro. Int J Cancer 117:1-7

6. Hamdi K, Castellon R (2005) Oleuropein, a non-toxiccoive iridoid, is an antitumor agent and cytoskeleton distruptor. Biochem Biophys Res Comm 334:769-778

7. Keys AB (1980) Seven countries: a multivariate analysis of death and coronary heart disease. Harvard University Press, Cambridge
8. Kuhajda FP (2000) Fatty-acid synthase and human cancer: new perspectives on its role in tumor biology. Nutrition 16:202-208

9. Lu S, Zhang X, Badawi AF, El-Sohemy A, Archer MC (2002) Cyclooxygenase-2 inhibitor celecoxib inhibits promotion of mammary tumorigenesis in rats fed a high fat diet rich in n-6 polyunsaturated fatty acids. Cancer Lett 184:7-12

10. Menendez JA, Lupu R (2006) Oncogenic properties of the endogenous fatty acid metabolism: molecular pathology of fatty acid synthase in cancer cells. Curr Opin Clin Nutr Metab Care 9:346-357

11. Menendez JA, Lupu R (2007) Fatty acid synthase and the lipogenic phenotype in cancer pathogenesis. Nat Rev Cancer 7:763-777

12. Menendez JA, Vazquez-Martin A, Oliveras-Ferraros C, GarciaVillalba R, Carrasco-Pancorbo A, Fernandez-Gutierrez A, Segura-Carretero A (2008) Analyzing effects of extra-virgin olive oil polyphenols on breast cancer-associated fatty acid synthase protein expression using reverse-phase protein microarrays. Int $\mathbf{J}$ Mol Med 22:433-439

13. Nemoto T, Terashima S, Kogure M, Hoshino Y, Kusakabe T, Suzuki T, Gotoh M (2001) Overexpression of fatty acid synthase in oesophageal squamous cell dysplasia and carcinoma. Pathobiology 69:297-303

14. Notarnicola M, Altomare DF, Calvani M, Orlando A, Bifulco M, D'Attoma B, Caruso MG (2007) Fatty acid synthase hyperactivation in human colorectal cancer: relationship with tumor side and sex. Oncology 71:327-332

15. Ogino S, Nosho K, Meyerhardt JA, Kirkner GJ, Chan AT, Kawasaki T, Giovannucci EL, Loda M, Fuchs CS (2008) Cohort study of fatty acid synthase expression and patient survival in colon cancer. J Clin Oncol 26:5713-5720

16. Obied HK, Prenzler PD, Konczak I, Rheman A, Robard K (2009) Chemistry and bioactivity of olive biophenols in some antioxidant and antiproliferative in vitro bioassays. Chem Res Toxicol 22:227-234

17. Owen RW, Giocosa A, Hull WE, Haubner R, Wurtele G, Spiegelhalder B, Bartsch H (2000) The antioxidant/anticancer potential of phenolic compounds isolated from olive oil. Eur J Cancer 36:1235-1247

18. Owen RW, Giacosa A, Hull WE, Haubner R, Wurtele G, Spiegelhalder B, Bartsch H (2000) Olive-oil consumption and health: the possible role of antioxidants. Lancet Oncol 1:107-112

19. Perona JS, Cabello-Moruno R, Ruiz-Gutierrez V (2006) The role of virgin olive oil components in the modulation of endothelial function. J Nutr Biochem 17:429-445

20. Rashid A, Pizer ES, Moga M, Milgraum LZ, Zahurak M, Pasternack GR, Kuhajda FP, Hamilton SR (1997) Elevated expression of fatty acid synthase and fatty acid synthetic activity in colorectal neoplasia. Am J Pathol 150:201-208

21. Serra-Majem L, Roman B, Estruch R (2006) Scientific evidence of interventions using the Mediterranean diet: a systematic review. Nutr Rev 64:S27-S47

22. Sofi F, Cesari F, Abbate R, Genuini GF, Casini A (2008) Adherence to Mediterranean diet and health status: meta-analysis. BMJ 337:a1344

23. Suying L, Archer MC (2005) Fatty acid synthase is a potential molecular target for the chemoprevention of breast cancer. Carcinogenesis 26(1):153-157

24. Swinnen JV, Heemers H, Deboel L, Foufelle F, Heyns W, Verhoeven G (2000) Stimulation of tumor-associated fatty acid synthase expression by growth factor activation of the sterol regulatory element-binding protein pathway. Oncogene 19:51735181

25. Trichopoulou A, Naska A, Orfanos P, Trichopoulos D (2005) Mediterranean diet relation to body mass index and waist-to-hip ratio: the Greek European prospective investigation into cancer and nutrition study. Am J Clin Nutr 82:935-940 
26. Visca P, Alo PL, Del Nonno F, Botti C, Trombetta G, Marandino F, Filippi S, Di Tondo U, Donnorso RP (1999) Immunohistochemical expression of fatty acid synthase, apoptotic-regulating genes, proliferatine factors, and ras protein product in nonneoplastic mucosa. Clin Cancer Res 5:4111-4118

27. Visioli F, Poli A, Gall C (2002) Antioxidant and other biological activities of phenols from olives and olive oil. Med Res Rev 22:65-75

28. Waterman E, Lockwood B (2007) Active components and clinical applications of olive oil. Altern Med Rev 12:331-342
29. Willett WC, Sacks F, Trichopoulou A, Drescher G, Ferro-Luzzi A, Helsing E et al (1995) Mediterranean diet pyramid: a cultural model for healthy eating. Am J Clin Nutr 61:1402-1406

30. Zhan Y, Ginanni N, Tota MR, Wu M, Bays NW, Richon VM et al (2008) Control of cell growth and survival by enzymes of the fatty acid synthesis pathway in HCT-116 colon cancer cells. Clin Cancer Res 14:5735-5742 